\title{
Statement of concern re: The effects of organic nitrates on osteoporosis: a systematic review
}

\author{
S. A. Jamal ${ }^{1,2}$ • L. S. Reid ${ }^{1}$ C. J. Hamilton ${ }^{1,3}$
}

Published online: 1 December 2016

(C) International Osteoporosis Foundation and National Osteoporosis Foundation 2016

\section{Erratum to: Osteoporos Int}

\section{DOI 10.1007/s00198-012-2262-9}

The Editors-in-Chief of Osteoporosis International would like to alert readers that the conclusions reached by this review article may be questionable, as they are based, in part, on two cited works that have been retracted:

- Jamal SA, Goltzman D, Hanley DA et al. (2009) Nitrate use and changes in bone mineral density: the Canadian Multicentre Osteoporosis Study. Osteoporos Int 20(5): 737-744. doi: 10.1007/s00198-008-0727-7

- Effect of nitroglycerin ointment on bone density and strength in postmenopausal women: a randomized trial. J Am Med Assoc 305(8) : 800-807. doi: 10.1001/jama.2015.18431

Consequently, readers are advised to interpret the conclusions reached in the article with caution.

The online version of the original article can be found at http://dx.doi. org/10.1007/s00198-012-2262-9.

S. A. Jamal

sophie.jamal@utoronto.ca

L. S. Reid

lauren.reid@wchospital.ca

C. J. Hamilton

celeste.hamilton@utoronto.ca

1 Women's College Research Institute, 790 Bay Street, 7th Floor, Toronto, Ontario M5G 1N8, Canada

2 Department of Medicine, Women's College Hospital, University of Toronto, 790 Bay Street, 7th Floor, Toronto, Ontario M5G 1N8, Canada

3 Department of Exercise Sciences, University of Toronto, 790 Bay Street, 7th Floor, Toronto, Ontario M5G 1N8, Canada 